\title{
Lidil
}

Revue de linguistique et de didactique des langues

\section{Nathalie Hirschsprung et Tony Tricot, Cosmopolite: méthode de français}

Paris, Hachette FLE, 2017, 224 p.

\section{Fabio Arismendi}

\section{OpenEdition}

Journals

Édition électronique

URL : http://journals.openedition.org/lidil/4842

DOI : $10.4000 /$ lidil.4842

ISSN : $1960-6052$

Éditeur

UGA Éditions/Université Grenoble Alpes

\section{Édition imprimée}

ISBN : 978-2-37747-048-8

ISSN : $1146-6480$

\section{Référence électronique}

Fabio Arismendi, « Nathalie Hirschsprung et Tony Tricot, Cosmopolite : méthode de français », Lidil [En ligne], 57 | 2018, mis en ligne le 01 mai 2018, consulté le 23 septembre 2020. URL : http:// journals.openedition.org/lidil/4842; DOI : https://doi.org/10.4000/lidil.4842

Ce document a été généré automatiquement le 23 septembre 2020

(C) Lidil 


\section{Nathalie Hirschsprung et Tony Tricot, Cosmopolite : méthode de français}

Paris, Hachette FLE, 2017, 224 p.

Fabio Arismendi

\section{RÉFÉRENCE}

Nathalie Hirschsprung et Tony Tricot, Cosmopolite : méthode de français, Paris, Hachette FLE, 2017, $224 \mathrm{p}$.

1 Cosmopolite est le nouveau manuel de FLE proposé par la maison d'édition Hachette et adressé à un public de grands adolescents et adultes, pour les niveaux A1 et A2. Comme option pédagogique, les auteurs proposent une démarche qu'ils qualifient d'actionnelle et qui suit les recommandations du Cadre européen commun de référence pour les langues. Il est cependant important de se demander en quoi ce manuel relève d'une démarche actionnelle.

2 Ce manuel est composé de huit dossiers contenant chacun six leçons. Tous les dossiers se composent d'une double page "Cultures", d'une page "Projet» et d'une page «DELF ». Chaque dossier débute sur une double page ayant pour but d'explorer les représentations des apprenants ainsi que de valoriser leurs connaissances antérieures. Dès ces premières pages, on propose la réalisation d'un projet de classe et d'un projet ouvert sur le monde que les apprenants construisent au fil des séquences. Ces projets sont adaptés au niveau des apprenants et ce sont les contenus présentés dans chaque leçon du dossier qui vont amener les apprenants à se préparer pour leur réalisation. Toutes les leçons proposent des tâches, souvent en collaboration, qui débouchent sur une production orale ou écrite. Pour ce faire, chaque leçon s'ouvre sur un document déclencheur, écrit ou oral. La grammaire, la phonétique et le lexique y sont intégrés par le biais de focus langue ou sons du français. Ces sections proposent une démarche 
inductive qui amène les apprenants à découvrir le fonctionnement de la langue en analysant des points précis dans les documents déclencheurs. Afin de permettre l'acquisition des compétences linguistiques nécessaires à la réalisation des tâches, on trouve une série d'exercices à la fin du manuel (« S'exercer ») ainsi que des activités de phonie-graphie.

Cosmopolite contient aussi un DVD-ROM pour l'élève, rassemblant tous les documents audios présents dans le livre ainsi que des séquences vidéo proposées pour la rubrique "Cultures». Ces documents accompagnés d'un parcours digital sont également disponibles sur le site internet de Hachette FLE. La collection contient un petit livre avec les transcriptions, les corrigés des exercices et un lexique multilingue. Enfin, elle comprend un cahier d'exercices. Ce cahier propose des activités de compréhension et de production, et des exercices permettant de systématiser le focus langue et la phonétique de chaque leçon. Les auteurs incluent également des activités d'autoévaluation et un CD-ROM. Tous ces outils devraient permettre le travail en autonomie de l'apprenant qui peut, par exemple, confronter ses propres progrès grâce au livret de transcriptions et corrigés.

4 Les thématiques abordées sont actuelles et les tâches proposées ressemblent en général à celles de la vie quotidienne telles que chercher un emploi ou préparer un voyage. Les choix des auteurs correspondent au niveau de progression selon les descripteurs des niveaux du CECRL. Les différents parcours pédagogiques présentent souvent des liens à des sites internet réels qui permettront aux apprenants d'approfondir les sujets traités.

5 Pour cette nouvelle série de manuels, les auteurs envisagent le français comme « langue internationale » et ce, grâce à leur expérience en tant que formateurs dans des contextes divers. Cela signifie que les contenus et les supports proposés ne se cantonnent pas uniquement à la France ou aux pays francophones comme cela a souvent été le cas dans les manuels de FLE. En revanche, les auteurs proposent de faire « un tour du monde » des pays " où la langue française est présente ». De ce fait, les enseignants et les étudiants de FLE trouveront quelques textes et documents produits par des locuteurs dont le français n'est pas la langue maternelle. Les thématiques de discussion ont ainsi une portée plus globale, mais toujours en lien avec la francophonie. De cette manière, il semble que l'approche choisie renforce l'idée suggérée par le titre de la série, Cosmopolite, à savoir une ouverture sur le monde ayant comme pivot central la langue française, très répandue au niveau international.

Certes, la tentative de proposer des projets et des tâches dans ce nouveau manuel permet d'observer un effort pour intégrer une perspective actionnelle, mais seulement sa mise en œuvre dans les classes de FLE permettra vraiment d'analyser dans quelle mesure il contribue à faire de la classe un espace vivement actionnel. 


\section{AUTEURS}

\section{FABIO ARISMENDI}

LIDILEM, Université Grenoble Alpes \& Escuela de Idiomas, Universidad de Antioquia 